\title{
Father Involvement in Education Predicates the Mental Health Status of Chinese Primary School Students
}

\author{
Junhua Zhang ${ }^{1, *}$, Siyuan Wang ${ }^{2} \&$ Yuan $\mathrm{Lu}^{3}$ \\ ${ }^{1}$ School of Education Science, Jiangsu Key Laboratory for Big Data of Psychology and Cognitive Science, Yancheng \\ Teachers University, Yancheng, China \\ ${ }^{2}$ School of Chinese Language and Culture, Nanjing Normal Universtiy, Jiangsu, China \\ ${ }^{3}$ Department of Autop Education, Soochow Youth Strong Culture Communication Co.Ltd, Suzhou, China \\ *Correspondence: School of Education Science, Jiangsu Key Laboratory for Big Data of Psychology and Cognitive \\ Science, Yancheng Teachers University, 50 Kaifang Road, Yancheng Teachers College, Yancheng City, 224002 \\ Jiangsu Province, China. E-mail: junhuazh2003@163.com
}

Received: June 23, 2019

Accepted: July 21, 2019 Online Published: August 15, 2019

doi:10.5430/wje.v9n4p65

URL: https://doi.org/10.5430/wje.v9n4p65

\begin{abstract}
Previous studies have shown that quality and the quantity of father involvement in education play an important role in children's development. The influence of father involvement in education on Chinese children's mental health status still needs further study. To understand the present situation of father involvement in education and its impact on children's mental health, this study will concentrate on the impact of father involvement on the mental health status of primary school students, This study surveyed 1669 primary school students in Yancheng, China. It was pointed out that $45.1 \%$ of fathers were not active in children's education, and $25.8 \%$ of fathers have not been sufficient time to accompany their children. Children's sex and grade were not associated with father involvement in education, which was linked to their father's occupation and education level. Father involvement dramatically affected primary school students' sensitive tendency and impulsive tendency. Father involvement can make children more optimistic and less focus on trifles and suspicious. More father involvement in education leads to better mental health status. These results suggest the importance of increasing father involvement in education in promoting mental health status in primary school students.
\end{abstract}

Keywords: father involvement, mental health status, primary school students, China

\section{Introduction}

Mental health problems are considered very common among children. Depending on Green et al 2004, about 1 in 10 children and adolescents had mental health needs in Great Britain(Green, McGinnity, Meltzer, Ford, \& Goodman, 2004). In China, the prevalence of mental disorders among students aged 6-16 years was $15.24 \%$ (95 CI: 15.49-16.97\%)(Qu, Jiang, Zhang, Wang, \& Guo, 2015). To promote children's mental health, it is very useful to identify protective factors(Profe \& Wild, 2017). As an important part of children's lives(Bernard, Whitson, \& Kaufman, 2015), the involvement of fathers may protect children from depression and delinquency(Dekovic, 1999).In the traditional social division of labor, mothers were asked to take care of their children while fathers were primarily responsible for raising families. Since the 1960s, there has been a growing focus on father's involvement (Lamb, 2000). In recent decades, there has been a growing emphasis on the relationship between fathers and children, and the involvement of fathers in children's education(Thapa \& Niehof, 2013). Fathers usually accompany their children through active physical engagement. These experiences can promote emotional connection(Coyl-Sheperd \& Newland, 2013). Many children reported that the nurturing and emotional aspects of father involvement were significant and meaningful, even aside from the tangible experience that they shared with their fathers(Goodsell \& Meldrum, 2010). It was found that high-quality father involvement has a positive effect on the development of children, such as healthier relationships, higher employment rates, and other favorable life quality. Tautolo found a significant correlation between father involvement and children's internalization and externalization(Tautolo, Schluter, \& Paterson, 2015). Yoon found that higher quality of father involvement was linked to lower levels of 
internalizing and externalizing behavior problems among preadolescents at risk of maltreatment(Yoon, Bellamy, Kim, \& Yoon, 2018).

Father involvement in education usually includes availability, interaction, and responsibility. Availability means the presence of the father, which is based on the amount of time fathers spend with their children. Interaction refers to the direct contact between fathers and children while responsibility refers to the role of fathers in determining the needs of their children and providing them with the resources available to them(Lamb, Pleck, Charnov, \& Levine, 1987). Fathers' education level, children gender and other factors are considered to have distinct influences on fathers' involvement. McConnell found a positive correlation between parental education and parent-child interaction quality (McConnell, Breitkreuz, \& Savage, 2011). Conger insisted on the unique influence of parents' level of education in family process(Conger, Conger, \& Martin, 2010). As to children by gender, Pleck found that fathers were more interested in interaction with their sons(Pleck, 1997). On the contrary, Wu found that father involvement had no relationship with children's gender and age(Wu, Chen, Liu, \& Xing, 2014). Quality and the quantity of father involvement in education play an important role in children's development. The amount of father-child time in educational activities was found to be associated with moderate to large improvements in children's cognitive development(Cano, Perales, \& Baxter, 2019). Opondo found that positive psychological and emotional aspects of father involvement in children's early upbringing, rather than the quantity of direct involvement may protect children from depressive symptoms in their future (Opondo, Redshaw, \& Quigley, 2017). Further studies have found that the quality of fathers' involvement is more important than time on children's development. (McWayne, Downer, Campos, \& Harris, 2013). Therefore, this study will focus on the influence of the time and quality of father involvement on children's mental health.

In contemporary Chinese families, many fathers are increasingly aware of their important role in the growth of children(Xu \& Xu, 2016). However, they usually do not have enough time with their children due to high work pressure (Rokicka, 2016). At present, it is worth for further discussion father involvement in education influence on children's mental health. Primary school students are in the critical period of physiological and psychological development, and various mental health problems are prone to occur. This study will concentrate on the impact of father involvement on the mental health status of primary school students in Yancheng, a small and medium-sized city in China. In sum, we have two hypotheses. 1. Fathers involvement is not abundant. 2 . The mental health status of primary school students is closely related to their father's involvement.

\section{Methods}

\subsection{Subjects}

Institutional Review Board (IRB) of Yancheng Teachers University granted ethical approval of this study. A letter informing children's right to withdraw and confidential promise was sent to parents a week before the survey began. Implied consent was acquired if parents did not refuse their children to take part in this study. For students higher than grade 3, questionnaires were filled out by students themselves. For students in grade 3 and younger, questionnaires were filled out by parents. A total of 2400 questionnaires were distributed and 1669 valid questionnaires were received, including 723 girls and 946 boys. The number of students from grade 1 to 6 was $553,361,284,174,159$ and 138 respectively. The age range is 6 to 12 . The mean (M) and standard deviation (SD) is 7.63 and 1.73 separately. The number of fathers with high school, college and postgraduate education is 627,948 and 94 respectively. The number of fathers from government institutions, public institutions, enterprise and self-employed was $127,324,531$ and 658 , respectively.

\subsection{Measurements}

Mental Health Test (MHT) scale was adopted by Bucheng Zhou and widely accepted to reflect individual mental health status and various anxiey issues(Wu, Qu, Wang, Tang, \& Sun, 2019; Zhou, 1991). MHT had 100 items divided into 8 content scales: Learning anxiety tendency, Social anxiety tendency, Loneliness tendency, Self-accusation tendency, Sensitive tendency, physical symptoms, phobia tendency, impulsive tendency. In short, higher score means more mental health problems.

Father involvement in education included two items. The first item is about the quality of father involvement, that is, my father involvement in education is. A. Active B. Passive. The second item is about the time of father involvement in education, that is, how many times a week does your father spends more than an hour with you. A, more than 3 times B, 1-2 times $\mathrm{C}$, hardly.

The highest educational level and occupation of their fathers, two indicators of social status, were also investigated. 
Educational level was assessed using the following categories: High school and lower, College and University, Postgraduate and higher. Occupations were classified using the following categories: government institutions, public institutions, enterprises, self-employed.

\subsection{Data Analyses}

Spss16.0 statistical software was used. The data was analyzed by descriptive statistics, Chi-square test, t-test and one-way ANOVA.

\section{Results}

\subsection{Statutes of Father Involvement}

As showed in table 1 , only $54.9 \%$ of fathers actively participated while still $45.1 \%$ fathers passively involved. About $74.2 \%$ of fathers can accompany with their children, while $25.8 \%$ of fathers cannot company with children usually.

Table 1. Father Involvement in Children's Education

\begin{tabular}{lccc}
\hline \multicolumn{1}{c}{ Division } & Level & Number & Percent (\%) \\
\hline my father involvement in & Active & 916 & 54.9 \\
education is & Passive & 753 & 45.1 \\
how many times a week does your & more than 3 times & 493 & 29.5 \\
father spends more than an hour & $1-2$ times & 746 & 44.7 \\
with you & hardly & 430 & 25.8 \\
\hline
\end{tabular}

As showed in table 2 and 3, there is no relationship between father involvement and children gender and grade. There was no significant difference in the involvement of fathers between boys and girls. There was no significant difference in the degree of father participation between different grades. The degree of father involvement was significantly related to the fathers' occupation and educational level. Compared with their counterpart, those fathers with low degree of education and self-employed tend to be less likely to accompany their children and passively participate in children's education.

Table 2. Factors That Influenced the Quantity of Father Involvement

\begin{tabular}{|c|c|c|c|c|}
\hline \multirow{2}{*}{ Factors } & \multirow[t]{2}{*}{ Level } & \multicolumn{3}{|c|}{$\begin{array}{c}\text { how many times a week does your father spends more than an hour } \\
\text { with you }\end{array}$} \\
\hline & & $\begin{array}{l}\text { more than } 3 \text { times } \\
(\mathrm{N}=493)\end{array}$ & $\begin{array}{l}1-2 \text { times } \\
(\mathrm{N}=924)\end{array}$ & $\begin{array}{c}\text { hardly } \\
(\mathrm{N}=555)\end{array}$ \\
\hline \multirow{3}{*}{ Child gender } & Girl & $201(27.8 \%)$ & $331(45.8 \%)$ & $191(26.4 \%)$ \\
\hline & Boy & $292(30.9 \%)$ & $415(43.9 \%)$ & $239(25.3 \%)$ \\
\hline & Chi-square & 1.85 & & \\
\hline \multirow{7}{*}{ Grade } & 1 & $174(31.3 \%)$ & $248(44.6 \%)$ & $134(24.1 \%)$ \\
\hline & 2 & $101(27.9 \%)$ & $153(42.3 \%)$ & $108(29.8 \%)$ \\
\hline & 3 & $88(31.4 \%)$ & $120(42.9 \%)$ & $72(25.7 \%)$ \\
\hline & 4 & $46(26.6 \%)$ & $82(47.4 \%)$ & $45(26.0 \%)$ \\
\hline & 5 & $46(28.8 \%)$ & $76(47.5 \%)$ & $38(23.8 \%)$ \\
\hline & 6 & $38(27.5 \%)$ & $67(48.6 \%)$ & $33(23.9 \%)$ \\
\hline & Chi-square & 7.05 & & \\
\hline \multirow{4}{*}{$\begin{array}{l}\text { Education level } \\
\text { of father }\end{array}$} & $\leq$ High school & $145(23.1 \%)$ & $263(41.9 \%)$ & $219(34.9 \%)$ \\
\hline & College & $31(32.7 \%)$ & $438(46.2 \%)$ & $200(21.1 \%)$ \\
\hline & $\geq$ Postgraduate & $38(40.4 \%)$ & $45(47.9 \%)$ & $11(11.7 \%)$ \\
\hline & Chi-square & $53.13 * * *$ & & \\
\hline \multirow{5}{*}{$\begin{array}{c}\text { Occupation of } \\
\text { father }\end{array}$} & Government & $54(42.5 \%)$ & $55(43.3 \%)$ & $18(14.2 \%)$ \\
\hline & $\begin{array}{l}\text { Public } \\
\text { institutions }\end{array}$ & $109(33.6 \%)$ & $153(47.2 \%)$ & $62(19.1 \%)$ \\
\hline & Enterprise & $182(34.3 \%)$ & $244(46.0 \%)$ & $105(19.8 \%)$ \\
\hline & Self-employed & $145(22.0 \%)$ & $284(43.2 \%)$ & $229(34.8 \%)$ \\
\hline & Chi-square & $67.40 * * *$ & & \\
\hline
\end{tabular}

$* * * \mathrm{p}<0.001$ 
Table 3. Factors That Influenced the Quality of Father Involvement

\begin{tabular}{|c|c|c|c|}
\hline \multirow{2}{*}{ Factors } & \multirow[t]{2}{*}{ Level } & \multicolumn{2}{|c|}{ my father involvement in education } \\
\hline & & Active & Passive \\
\hline \multirow[t]{3}{*}{ Child gender } & Girl & $405(56.0 \%)$ & $318(44.0 \%)$ \\
\hline & Boy & $511(54.0 \%)$ & $435(46.0 \%)$ \\
\hline & Chi-square & 0.66 & \\
\hline \multirow[t]{7}{*}{ Grade } & 1 & $297(53.4 \%)$ & $259(46.6 \%)$ \\
\hline & 2 & $190(52.5 \%)$ & $172(47.5 \%)$ \\
\hline & 3 & $156(55.7 \%)$ & $124(44.3 \%)$ \\
\hline & 4 & $91(52.6 \%)$ & $82(47.4 \%)$ \\
\hline & 5 & $96(60.0 \%)$ & $64(40.0 \%)$ \\
\hline & 6 & $86(62.3 \%)$ & $52(37.7 \%)$ \\
\hline & Chi-square & 6.53 & \\
\hline \multirow[t]{4}{*}{ Education level of father } & $\leq$ High school & $313(49.9 \%)$ & $314(50.1 \%)$ \\
\hline & College & $541(57.1 \%)$ & $407(42.9 \%)$ \\
\hline & $\geq$ Postgraduate & $62(66.0 \%)$ & $32(34.0 \%)$ \\
\hline & Chi-square & $12.71 * *$ & \\
\hline \multirow[t]{5}{*}{ Occupation of father } & Government institutions & $88(69.3 \%)$ & $39(30.7 \%)$ \\
\hline & Public institutions & $191(59.0 \%)$ & $133(41.0 \%)$ \\
\hline & Enterprise & $326(61.4 \%)$ & $205(38.6 \%)$ \\
\hline & Self-employed & $299(45.4 \%)$ & $359(54.6 \%)$ \\
\hline & Chi-square & $45.60 * * *$ & \\
\hline
\end{tabular}

$* * * \mathrm{p}<0.001 ; * * \mathrm{p}<0.01$

\subsection{Father Involvement and Children'Mental Health}

The mental health subscale of primary school students was tested according to the quality of father involvement. We divided the quality of father involvement into active and passive. T-test was used to compare the MHT score of students with active father involvement and those with passive father involvement. As showed in Table 4 , there were statistically significant differences $(p<0.05)$ between the two types of students in Sensitive tendency and impulsive tendency, and the students with passive father involvement scored higher than the other students.

The mental health subscale of primary school students was tested according to the time of father involvement. We divided the time of father involvement into three types, including more than 3 times, 1-2 times and hardly F-test was used to compare the MHT score of students with three types of father involvement. As showed in Table 5, there were statistically significant differences $(p<0.05)$ among three types of students in impulsive tendency, LSD test showed that impulsive tendency were significantly higher in "hardly" group than other groups. Students with fewer fathers accompany had significant highest impulsive tendency.

Table 4. The Effect of the Quality of Father Involvement on Children's Mental Health

\begin{tabular}{lccc}
\hline & \multicolumn{2}{c}{ my father involvement in educationis } \\
\cline { 2 - 3 } \multicolumn{1}{c}{ Total } & Active(N=916) & Passive(N=753) & $\mathrm{t}$ \\
\cline { 2 - 4 } Learning anxiety tendency & $29.64 \pm 12.39$ & $30.68 \pm 11.90$ & 1.73 \\
Social anxiety tendency & $6.77 \pm 2.99$ & $6.90 \pm 3.04$ & 0.88 \\
Loneliness tendency & $3.66 \pm 1.98$ & $3.79 \pm 1.90$ & 1.32 \\
Self-accusation tendency & $1.45 \pm 1.70$ & $1.51 \pm 1.79$ & 0.72 \\
Sensitive tendency & $4.82 \pm 2.45$ & $4.92 \pm 2.28$ & 0.81 \\
Physical symptoms & $4.76 \pm 2.20$ & $4.98 \pm 2.19$ & $2.05^{*}$ \\
Phobia tendency & $3.66 \pm 2.16$ & $3.78 \pm 2.16$ & 1.10 \\
Impulsive tendency & $2.99 \pm 2.43$ & $3.07 \pm 2.41$ & 0.71 \\
\hline
\end{tabular}


Table 5. The Effect of the Quantity of Father Involvement on Child's Mental Health

\begin{tabular}{|c|c|c|c|c|c|}
\hline & \multicolumn{5}{|c|}{ how many times a week does your father spends more than an hour with you } \\
\hline & $\begin{array}{c}\text { more than } 3 \text { times a } \\
(\mathrm{N}=493)\end{array}$ & $\begin{array}{c}1-2 \text { times } b \\
(\mathrm{~N}=924)\end{array}$ & $\begin{array}{l}\text { hardly c } \\
(\mathrm{N}=555)\end{array}$ & $\mathrm{F}$ & LSD \\
\hline Total & $30.12 \pm 12.60$ & $29.54 \pm 12.00$ & $31.09 \pm 11.96$ & 2.20 & \\
\hline Learning anxiety tendency & $6.84 \pm 3.06$ & $6.74 \pm 2.94$ & $6.96 \pm 3.07$ & 0.71 & \\
\hline Social anxiety tendency & $3.71 \pm 2.02$ & $3.68 \pm 1.93$ & $3.79 \pm 1.87$ & 0.45 & \\
\hline Loneliness tendency & $1.46 \pm 1.72$ & $1.43 \pm 1.75$ & $1.56 \pm 1.76$ & 0.71 & \\
\hline Self-accusation tendency & $4.92 \pm 2.45$ & $4.79 \pm 2.35$ & $4.92 \pm 2.34$ & 0.61 & \\
\hline Sensitive tendency & $4.81 \pm 2.20$ & $4.78 \pm 2.21$ & $5.04 \pm 2.16$ & 1.98 & \\
\hline Physical symptoms & $3.76 \pm 2.27$ & $3.60 \pm 2.05$ & $3.86 \pm 2.22$ & 2.18 & \\
\hline Phobia tendency & $3.02 \pm 2.41$ & $2.97 \pm 2.43$ & $3.12 \pm 2.43$ & 0.49 & \\
\hline Impulsive tendency & $1.59 \pm 1.85$ & $1.55 \pm 1.79$ & $1.86 \pm 1.98$ & $4.01 *$ & $\mathrm{a}, \mathrm{b}<\mathrm{c}$ \\
\hline
\end{tabular}

\section{Discussion}

\subsection{Current Situations of Father Involvement}

More than $54 \%$ of fathers actively participated in children's education, while nearly half of the fathers are passive in the children's education. Therefore, the first hypotheses that fathers involvement is not abundant is confirmed. The results are consistent with previous studies. In a survey of more than 10, 000 parents of primary and secondary school students, All-China Women's Federation(ACWF) found that nearly half of fathers in their families were absent from their children's education(Wang, 2015). In contemporary society, most fathers are not only responsible for raising the family, they also need to spend more time with their children.

There was no significant relationship between the degree of father involvement and the gender and grade of children. This conclusion is inconsistent with a previous study in the United States. Age and gender composition of the children were found to be related to father involvement and fathers in the United States were more involved in boys and older children(Hofferth \& Anderson, 2003; Raley \& Bianchi, 2006). However, our research conclusions are consistent with Wu's the findings in China (Wu et al., 2014). It may be related to the impact of family planning policy in China. Most families have only one child, and many fathers give equal attention and care to both boys and girls.(Chen, Dai, Cehn, \& Yang, 2015)

Education level and occupation of fathers had a significant impact on father involvement. It is in line with previous studies(Wu et al., 2014). First, highly educated fathers can provide more resources for their children, especially in activities that require more knowledge and academic support. Low education is usually linked with low earnings, which are to some extent a barrier to fathers' involvement with their child(Guarin \& Meyer, 2018). Second, highly educated fathers are likely to go beyond the traditional division of labor between men and women and may invest more time and energy in children's education(Y. Xu, Ji, \& Zhang, 2006).

McGill found that fathers' occupation was not related to father involvement(McGill, 2014). Nevertheless, Torres found that father involvement was related to the occupational status of both parents(Torres, Verissimo, Monteiro, Ribeiro, \& Santos, 2014).Our results support the latter. This is partly because self-employed fathers have less regular working hours and are more stressed than those in government or public institutions. Fathers in government or public institutions are able to be more involved in their children's work due to having more control over their work schedules(Marsiglio, 1991).

\subsection{Primary School Students' Mental Health and Fathers Involvement}

There is a big difference between active and passive father involvement when it comes to children's allergies tendency. When father involvement is passive, children tend to worry about small things. Therefore, the second hypotheses that mental health status of primary school students is closely related to their father's involvement in education is also confirmed. Previous studies also found that the role of father is very important in the formation of the children's healthy state of mind(Jin \& Lan, 2014).

Father involvement can make children more optimistic and less focus on trifles and suspicious. As far as impulsive tendency are concerned, father involvement helps children more stable and peaceful, less impulsive or violent. When mothers are with their child, they often act as a caregiver. One of their most important jobs is to make sure their children are well fed, well dressed, and so on. As a result, mothers often engage in quiet activities with their children. In contrast, fathers like to play games requiring physical strength and movement, such as tickling, lifting, hiding and 
seeking, catching and so on. As a result, children experience a wide range of emotions while playing with their father, such as feeling "wow, so nervous, so scared, so fun." At the same time, children also learn a lot of emotional experience and interpersonal skills, which are very helpful for children's future interpersonal communication.

In conclusion, the higher level of father involvement, the stronger their children's psychological adaptability and the better mental health. If the child does not have the active father involvement during the growth process, it is easy to lead to the child's personality and emotional defects. Fathers with lower education and self-employment are likely to spend less time with their children and be more passive in their company. Strategies should be taken to raise their awareness.

\section{Practical Implication and limitations}

Family education calls for the participation of father. Fathers, especially those who are less educated or self-employed in small and medium-sized city in China, should learn to express love correctly, and spend more time with children.

Parent-training program is found helpful in increasing parenting skills and reducing children' negative behaviors(Vazquez, Cruz Molina, Ramos, \& Artazcoz, 2019). The effectiveness of online parenting program has also been confirmed by some studies (Toombs, Unruh, \& McGrath, 2018). It is recommended that these effective programs be incorporated into the training projects to enhance involvement of fathers, especially those with low education level and self-employed. More effective ways to encourage more father involvement in children's education are needed in future studies.

This study had some limitations. First, self-reported data was used in this study, which may be influenced by individual subjective evaluation and external background factors. High-quality scales should be used to objectively measure father involvement in education in future studies. Second, parents fill out some questionnaires, which may affect the homogeneity of data. Third, lack of control over other factors may affect the relationship between father involvement and their children' mental health.

\section{Conclusions}

Based on surveies from 1669 primary school students, this study focused on the impact of father involvement on the mental health status of primary school students. It was found that $45.1 \%$ of fathers were not active in children's education, and $25.8 \%$ of fathers have not been sufficient time to accompany their children. Father involvement in education was linked to father's occupation and education level. Father involvement dramatically affected primary school students' sensitive tendency and impulsive tendency. Father involvement can make children more optimistic and less focus on trifles and suspicious. More father involvement in education leads to better mental health status. These results suggest the importance of increasing father involvement in education in promoting mental health status in primary school students.

Informed consent: Informed consent was obtained.

\section{Acknowledgments}

The authors would like to thank the participants and other investigators involved.

Authors contributions: JZ and SW are co-first authors. JZ and SW equally contributed in conducting the whole study, since the development of the research design. YL collected the data and performed the literature review. SW prepared the initial draft and JZ arranged the final manuscript. After the final version had been read and approved, it was critically revised by all the authors.

Funding: None

Availability of data and materials: The data sets used and/or analysed during the current study is available from the corresponding author on reasonable request.

\section{References}

Bernard, S. N., Whitson, M., \& Kaufman, J. (2015). The moderating effect of positive father engagement and accessibility on a school-based system of care intervention for mental health outcomes of children. Journal of Child and Family Studies, 24(10), 2923-2933. https://doi.org/10.1007/s10826-014-0096-0 
Cano, T., Perales, F., \& Baxter, J. (2019). A matter of time: father involvement and child cognitive outcomes. Journal of Marriage and Family, 81(1), 164-184. https://doi.org/10.1111/jomf.12532

Chen, Y., Dai, Y., Cehn, H., \& Yang, T. (2015). The influence of father's involvement on the mental health of middle school students. Chinese Journal of School Health, 36(11), 1728-1731.

Conger, R. D., Conger, K. J., \& Martin, M. J. (2010). Socioeconomic status, family processes, and individual $\begin{array}{lllll}\text { development. Journal of Marriage and Family, } & \text { 72(3), 685-704. }\end{array}$ https://doi.org/10.1111/j.1741-3737.2010.00725.x

Coyl-Sheperd, D., \& Newland, L. (2013). Mothers' and fathers' couple and family contextual influences, parent involvement, and school-age child attachment. Early Child Development and Care, 183(3-4), 553-569. https://doi.org/10.1080/03004430.2012.711599

Dekovic, M. (1999). Risk and protective factors in the development of problem behavior during adolescence. Journal of Youth and Adolescence, 28(6), 667-685. https://doi.org/10.1023/A:1021635516758

Goodsell, T. L., \& Meldrum, J. T. (2010). Nurturing fathers: a qualitative examination of child-father attachment. Early Child Development and Care, 180(1-2), 249-262. https://doi.org/10.1080/03004430903415098

Green, H., McGinnity, A., Meltzer, H., Ford, T., \& Goodman, R. (2009). Mental health of children and young people in great britain 2004. Mental Health of Children \& Young People in Great Britain, 15(1-2), 185-187. https://doi.org/10.1037/e557702010-00

Guarin, A., \& Meyer, D. R. (2018). Are low earnings of nonresidential fathers a barrier to their involvement with children? Children and Youth Services Review, 91, 304-318. https://doi.org/10.1016/j.childyouth.2018.06.023

Hofferth, S., \& Anderson, K. (2003). Are all dads equal? Biology versus marriage as a basis for paternal investment. Journal of Marriage and Family, 65, 213-232. https://doi.org/10.1111/j.1741-3737.2003.00213.x

Jin, C., \& Lan, L. (2014). A Meta-analysis of the difference between juvenile delinquents and ordinary juveniles in parenting styles. Chinese Journal of Special Education, 21(02), 90-96.

Lamb, M. E. (2000). The history of research on father involvement. Marriage \& Family Review, 29(2-3), 23-42. https://doi.org/10.1300/J002v29n02_03

Lamb, M., Pleck, J., Charnov, E., \& Levine, J. (1987). A biosocial perspective on paternal behavior and involvement. In J. B. Lancaster, J. Altmann, A. S. Ross, \& L. R. Sherrod (Eds.), Parenting across the life span: Biosocial dimensions (pp. 111-141). New York: Aldine de Gruyter.

Marsiglio, W. (1991). Paternal engagement activities with minor children. Journal of Marriage and the Family, 53(4), 973-986. https://doi.org/10.2307/353001 doi:10.2307/353001

McConnell, D., Breitkreuz, R., \& Savage, A. (2011). From financial hardship to child difficulties: main and moderating effects of perceived social support. Child Care Health and Development, 37(5), 679-691. https://doi.org/10.1111/j.1365-2214.2010.01185.x

McGill, B. S. (2014). Navigating new norms of involved fatherhood employment, fathering attitudes, and father involvement. Journal of Family Issues, 35(8), 1089-1106. https://doi.org/10.1177/0192513x14522247

McWayne, C., Downer, J. T., Campos, R., \& Harris, R. D. (2013). Father involvement during early childhood and its association with children's early learning: a meta-analysis. Early Education and Development, 24(6), 898-922. https://doi.org/10.1080/10409289.2013.746932

Opondo, C., Redshaw, M., \& Quigley, M. A. (2017). Association between father involvement and attitudes in early child-rearing and depressive symptoms in the pre-adolescent period in a UK birth cohort. Journal of Affective Disorders, 221, 115-122. https://doi.org/10.1016/j.jad.2017.06.010

Pleck, H. (1997). Paternal involvement: Levels, sources, and consequences. In M. Lamb (Ed.), The role of the father in child development (pp. 66-103). NewYork: Wiley.

Profe, W., \& Wild, L. G. (2017). Mother, father, and grandparent involvement: associations with adolescent mental health and substance use. Journal of Family Issues, 38(6), 776-797. https://doi.org/10.1177/0192513x15583069

Qu, Y., Jiang, H., Zhang, N., Wang, D., \& Guo, L. (2015). Prevalence of mental disorders in 6-16-year-old students in Sichuan province, China. Int $J$ Environ Res Public Health, 12(5), 5090-5107. https://doi.org/10.3390/ijerph120505090 
Raley, S., \& Bianchi, S. (2006). Sons, daughters, and family processes: Does gender of children matter. Annual Review of Sociology, 32, 401-421. https://doi.org/10.2307/29737745

Rokicka, M. (2016). Do mothers' and fathers' work involvement matter for teenagers' school outcomes? British Educational Research Journal, 42(1), 117-134. https://doi.org/10.1002/berj.3191

Tautolo, E. S., Schluter, P. J., \& Paterson, J. (2015). Pacific father involvement and early child behaviour outcomes: Findings from the Pacific Islands families study. Journal of Child and Family Studies, 24(12), 3497-3505. https://doi.org/10.1007/s10826-015-0151-5

Thapa, D. K., \& Niehof, A. (2013). Women's autonomy and husbands' involvement in maternal health care in Nepal. Soc Sci Med, 93, 1-10. https://doi.org/10.1016/j.socscimed.2013.06.003

Toombs, E., Unruh, A., \& McGrath, P. (2018). Evaluating the parent-adolescent communication toolkit: Usability and preliminary content effectiveness of an online intervention. Nursing open, 5(1), 29-36. https://doi.org/10.1002/nop2.107

Torres, N., Verissimo, M., Monteiro, L., Ribeiro, O., \& Santos, A. J. (2014). Domains of father involvement, social competence and problem behavior in preschool children. Journal of Family Studies, 20(3), 188-203. https://doi.org/10.1080/13229400.2014.11082006

Vazquez, N., Cruz Molina, M., Ramos, P., \& Artazcoz, L. (2019). Effectiveness of a parent-training program in Spain: reducing the Southern European evaluation gap. Gaceta Sanitaria, 33(1), 10-16. https://doi.org/10.1016/j.gaceta.2017.06.005

Wang, D. (2015, Dec 24). National family education survey: nearly half of fathers are "absent" their children's education. Beijing Daily. Retrieved from http://www.xinhuanet.com/local/2015-12/24/c_128562366.htm

Wu, W., Qu, G. B., Wang, L. L., Tang, X., \& Sun, Y. H. (2019). Meta-analysis of the mental health status of left-behind children in China. Journal of Paediatrics and Child Health, 55(3), 260-270. https://doi.org/10.1111/jpc.14349

Wu, X., Chen, L., Liu, C., \& Xing, X. (2014). The characteristics of father involvement and its related influencing factors. Journal of South China Normal Univeristy (Social Science Edition), 59(6), 88-96.

$\mathrm{Xu}, \mathrm{Q} .$, \& Xu, Q. (2016). Father's role in the contemporary Chinese family. Cham: Springer International Publishing Ag.

Xu, Y., Ji, L., \& Zhang, W. (2006). Urban fathers involvement in children-parenting and its relationship with gender roles. Psychological develpoment and education, 22(3), 35-40.

Yoon, S., Bellamy, J. L., Kim, W., \& Yoon, D. (2018). Father involvement and behavior problems among preadolescents at risk of maltreatment. Journal of Child and Family Studies, 27(2), 494-504. https://doi.org/10.1007/s10826-017-0890-6

Zhou, B. (1991). Mental Health of Test(MHT). Shanghai: East China Normal University Press, 3-12. 